\title{
Redes tecnossociais e democratização das políticas públicas
}

\section{Resumo}

Examinar a ampliação do uso de TICs por organizações sociais e governamentais na gestão da cidade é o objetivo do presente estudo. Nossa intenção é entender de que forma as tecnologias da informação e comunicação podem ser uma via alternativa que redefine as relações entre Estado e sociedade, substituindo políticas urbanas tradicionais por formas colaborativas de interação dos atores sociais. Entre os resultados alcançados pela pesquisa, é possível destacar a elaboração de uma metodologia capaz de mapear os princípios de organização, articulação, conexão e interação que constituem a existência de redes tecnossociais. A aplicação da metodologia nas cidades do Rio de Janeiro e de São Paulo demonstrou indicadores, gráficos e práticas políticas. A análise desses dados revela como as redes se constituem por uma arquitetura móvel, fluída, flexível, organizadas em torno de políticas comuns de ação e formadas por uma identidade coletiva que aproxima os atores das redes tecnossociais. Os princípios que mediam esta coesão são de compartilhamento, confiança e solidariedade, que redefinem as formas da organização do poder em direção a alternativas de organização política e desenvolvimento social.

Palavras-chave: Redes tecnossociais. Políticas públicas. Democracia. Tecnologias da comunicação e informação. Inovação social.

* Prof. Dr. Adjunto IV, Instituto de Pesquisa e planejamento Urbano e regional - IPPUR/UFRJ. 


\section{Introdução}

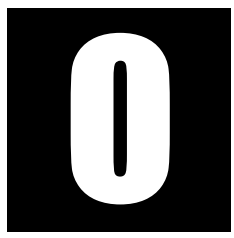

presente estudo interroga sobre a ampliação do uso de Tecnologias de Informação e Comunicação - TICs por atores públicos e privados. O objetivo é observar a inovação social que as TICs produzem nas políticas públicas para analisar as transformações que as tecnologias suscitam na política. Trata-se de entender de que forma as tecnologias da informação e comunicação podem ser uma alternativa de redefinição das relações entre Estado e sociedade, substituindo políticas urbanas tradicionais por formas alternativas de interação social, mediada por redes tecnossociais. Trata-se de examinar a realidade da disseminação das TICs no âmbito do Estado e da sociedade civil e de seus efeitos sobre a organização de políticas públicas para a gestão das cidades. ${ }^{1}$

O nosso estudo se debruça sobre os efeitos da sociedade da informação sobre a esfera política, essa advertência é importante porque ela nos ajuda a focar no objeto do conhecimento proposto para analise. Para tanto, a pesquisa realizada tem como ponto de partida examinar as condições reais e as configurações das redes tecnossociais e seu uso como mecanismo de coordenação social, para identificar o uso de redes telemáticas e os seus efeitos sobre a gestão democrática da cidade. É preciso distinguir rede telemáticas de redes tecnossociais. A primeira está referida ao suporte técnico propriamente dito, no que se refere à infraestrutura física das redes. Enquanto que nas redes tecnossociais estão referidas as relaçóes que se estabelecem entre atores que formam redes pela utilização do suporte telemático. Por isso é preciso decantar às duas dimensões uma primeira técnica e outra relacional de natureza social.

\footnotetext{
1 O presente artigo é um resultado do projeto de pesquisa de EGLER, Tamara Tania Cohen, "Redes tecnossociais e gestão democrática da cidade", premiado na concorrência internacional do Registro Geral de Endereçamento da Internet, para América Latina e o Caribe - LACNIC, no programa Frida, Fundo Regional para o desenvolvimento da Internet para a América Latina e o Caribe, disponível em http://programafrida.net/pt/.
} 
Esse posicionamento analítico é importante porque objetiva analisar formas alternativas de organização do poder, para além das formas tradicionais da máquina burocrática do Estado. O nosso entusiasmo com essa investigação está focado nessa decisão metodológica e nos seus efeitos sobre a compreensão dos processos sociais decorrentes da sociedade da informação. Trata-se de sair de um posicionamento analítico que explora as potencialidades das tecnologias no futuro, para entrar no mundo social de verdade, feito de relações sociais e tecnológicas no presente.

A nossa expectativa é que o uso das redes possa vir a ser um instrumento de inovação das relações políticas. Nesse contexto, é possível observar, por um lado, o esgotamento do modelo de governo municipal de estrutura burocrática, centralmente organizada e politicamente autoritária; e, por outro lado, as múltiplas possibilidades de associação virtual das novas tecnologias de comunicação e informação. Essas novas condições possibilitam formas alternativas de organização de políticas públicas, interação social e ação política, que podem transformar a participação cidadã e democratizar a gestão das cidades.

Para avançar nessa direção é preciso mapear o debate. A literatura do campo da sociedade da informação pode ser dividida em dois posicionamentos, um primeiro mais crítico e um segundo mais otimista relativo aos efeitos sociais da inovação tecnológica. Na primeira formulação, os autores alertam para os perigos dos efeitos da tecnologia que conduz para o processo de globalização e como os seus resultados podem ser lidas por novas estratégias de dominação. Esse processo é compreendido como modelo técnico único que se expande de forma rizomática e que se sobrepõe à natureza humana, transforma a hierarquia das escalas, produzindo uma natureza una e socialmente fragmentada em benefício de firmas, Estados e classes hegemônicas. Os autores analisam a importância das redes na constituição de um poder que se impõe acima das 
tradicionais fronteiras dos Estados-nação, em que o mando é exercido diretamente sobre a produção de novas subjetividades coletivas, associadas agora à produção de mercadorias simbólicas. Mais claramente, é preciso analisar como os processos advindos com as novas tecnologias transformam a estratégia, a ordem espacial e temporal, os atores e os objetos de sua produção, e nos convidam a examinar as formas específicas para a realização de novas formas de dominação das nações mais ricas sobre as mais pobres (SANTOS, 1996, 1994 ; HARDT; NEGRI, 2000).

Num posicionamento analítico mais otimista, reconhecemos formulações alternativas que se debruçam sobre a interpretação da natureza do espaço informacional, onde se afirma que se trata de um espaço feito de conhecimentos, saberes e potências que permitem novas formas de constituição do social. Esses autores consideram como as novas tecnologias produzem um ciberespaço, como um meio de comunicação, que tem uma forma e um conteúdo indeterminado, que transforma a comunicação intelectual e permite a constituição de novos laços sociais. É um suporte técnico para formação de novos coletivos que possibilitam formas alternativas de espaço, de vida e de movimento. Compreende a tecnologia como uma possibilidade de comunicação simbólica entre os homens, que alteram as experiências de formação do espaço público e de poder, que geram culturas e identidades específicas. Considera, sobretudo, um processo que inaugura uma nova cultura de liberdade, dada por novas possibilidades de interatividade que permitem novas formas da interação social, novas determinações econômicas, políticas e culturais, definindo uma nova sociedade em rede, quando as formas de utilização da tecnologia são determinantes nos processos de transformação da sociedade (LEVY, 1993; 1999a, 1999b; CASTELLS, 1999a, 1999b). Trata-se, portanto, de duas formas de interpretar a sociedade da informação, uma primeira que faz a sua crítica associada ao desvendamento de estratégias que definem as formas como são utiliza- 
das as redes, para ampliar o poder de dominação econômica e política. Um segundo posicionamento mais otimista que procura analisar seus efeitos sobre a vida cotidiana, a formação de identidades, as possibilidades de estabelecer um lugar-comum, e observam suas potencialidades na formação de novos espaços de cooperação que busquem, na experiência das redes, a formação de um novo espaço público de ação coletiva que se forma em benefício da emancipação social.

O nosso estudo tem um posicionamento analítico que valoriza a experiência de utilização das redes. Procura analisar seus efeitos na formação de um espaço público virtual que permita a realização de um lugar comum para o exercício da ação política em beneficio da defesa da dos interesses coletivos. Trata-se de um esforço analítico que procura reconhecer as especificidades dos meios de comunicação que se estruturam através das redes.

Essa interlocução com os autores do campo permite mapear o modo como o debate está construído em dois posicionamentos: o primeiro, que avalia o uso das redes para ampliar os processos de dominação econômica e política; o segundo, que avalia suas potencialidades para o desenvolvimento e emancipação social. Certamente a técnica em si não tem esse poder de dominação ou emancipação. A investigação proposta é examinar de que forma podemos avançar no sentido de identificar como as redes técnicas são utilizadas para a formação de um espaço público virtual. Compreendemos que os dois pocionamentos não se excluem, eles se complementam. As redes são utilizadas para a dominação e para a emancipação. Em outros momentos de nossa pesquisa elas foram examinadas para analisar as formas de dominação (EGLER, 2003, 2005). Depende como, por que e para quem elas são utilizadas.

É no importante estudo de Maia que encontramos o foco nas redes tecnossociais e seus efeitos sobre a formação de uma esfera pública virtual, quando ela analisa a importância das redes técnicas no estabele- 
cimento de um espaço de interação que amplia o poder de ação social. Compreende a esfera pública como o lugar dos interesses comuns e do planejamento da ação. E ilumina a problemática quando classifica as diferentes esferas de interação social no mundo virtual e define: interações simples - conversas na vida cotidiana; fóruns mais organizados - movimentos sociais e associações; e sistema político-formal - governo eletrônico. Quando as NTIC possibilitam a formação de novos fóruns cívicos pelo desenvolvimento técnico de plataformas de diálogo que possibilitam a criação de espaços públicos virtuais (MAIA, 2002).

As redes tecnossociais possibilitam a emergência de um espaço de comunicação virtual de todos para todos - formas de conectividade que permitem que a qualquer momento possamos nos conectar a qualquer pessoa ou a um banco de dados. Essa multiplicidade de canais possibilita uma nova forma de coletividade, onde os indivíduos estão em contínua comunicação - uma rede tecnossocial (OLIVEIRA, 2006). Essa rede possibilita uma mediação entre diferentes atores para a defesa dos interesses coletivos. Ela pode incluir redes sociais, organizações governamentais, empresas privadas e cidadãos comuns, possibilitando formas alternativas de unificação da esfera pública com a esfera privada. Trata-se da possibilidade de construção de um espaço público virtual para o exercício da vontade coletiva (HABERMAS, 1996).

Era preciso encontrar na literatura um conceito de rede que nos permitisse avançar na pesquisa. É na preciosa contribuição de Ilse Scherer Warren que encontramos como as redes se constituem em espaços de intercâmbio, negociação e definição de conflitos e de resistência aos adversários e aos mecanismos de descriminação, dominação e de exclusão. Elas definem seus adversários, reconhecem suas estratégias de ação e contrapõem uma direção alternativa por meio da organização do seu movimento e poderão ser virtuais ou presencias (SCHERER, 2003). 
A importância da pesquisa reside em compreender onde as redes apresentam uma nova possibilidade de exercício da política, e onde as TICs se constituem em dispositivos tecnológicos que potencializam as suas formas de organização. As redes constituem uma nova forma de constituição do Nós e da sua ação e têm por pressuposto a ação coletiva e direta dos seus membros. Os atores unem-se para potencializar suas possibilidades para o enfrentamento de problemas sociais, e são redefinidas as relações de poder, porque as redes assumem para si tarefas que são tradicionalmente desempenhadas pelo Estado. Essa possibilidade de associação, que vai além da representação política, coloca os associados como principais protagonistas do projeto de ação. Trata-se, pois, de eliminar a intermediação e de possibilitar formas diretas de ação e de transformação (EGLER, 2005). O que possibilita inaugurar novas relações de organização e de possibilidades de ação para a transformação das políticas urbanas, nas quais os atores sociais estão diretamente implicados com o seu objeto de ação.

Isso é muito importante porque abre uma nova concepção na formação do Nós. Que nos ajuda a expressar à dimensão social da existência humana. Os pronomes revelam os sujeitos sociais, o Eu está referido à condição individual, o Tu, ao igual que está mais próximo, e o Ele , ao mais distante, ao diferente. O Nós, está referido à qualidade interna, que reúne um certo número de indivíduos em comunidade (BARTHOLO, 2001). As novas tecnologias permitem um suporte técnico que define novas relações espaços-temporais e permite a ampliação das possibilidades de formação do Nós. Trata-se de uma expansão da complexidade e da simultaneidade do espaço e do tempo.

A invenção das redes tecnossociais permite possibilidades de participação que ainda não haviam sido imaginadas (GERSTLÉ, 2003). Essa é a questão que propomos investigar e analisar, as possibilidades dadas pela tecnologia para reinventar a política. Importa observar de que forma as 
tecnologias possibilitam a redefinição das relações entre Estado e atores sociais, no que se refere à formulação e implementação de políticas públicas, de processos de democratização da gestão da cidade e da transformação das condições de vida urbana.

As nossas perguntas principais podem ser enunciadas da seguinte forma:

Quais metodologias nos permitem identificar, mapear e compreender as práticas sociopolíticas, no contexto da gestão democrática da cidade e diante do fato de estas serem crescentemente mediadas por dispositivos tecnológicos? Quer dizer, era necessário examinar os efeitos do desenvolvimento tecnológico sobre as formas de organização das políticas públicas e das práticas sociopolíticas de seus membros associados.

A pesquisa foi estruturada em dois eixos de investigação: um primeiro eixo para analisar a dimensão técnica, objetiva, material e tangível; e um segundo para reconhecer as dimensões: social, subjetiva, imaterial e intangível das redes tecnossociais. $\mathrm{O}$ avanço na formulação dessa metodologia se realiza a partir da compreensão de que era preciso reconhecer as teorias, os processos e os procedimentos que deveriam ser observados para a formulação do método a ser proposto.

O primeiro eixo estava associado à dimensão objetiva lida na arquitetura das redes tecnossociais, para fazer aparecer os fluxos de comunicação que conectam os diferentes atores das redes de políticas públicas. Para isso, foi necessário observar as relações objetivas e concretas dos atores em rede e analisar as suas articulações. Para avançar nessa direção, foi importante compreender o processo de conectividade em rede, do posicionamento dos atores, e das estruturas de compartilhamento e de integração.

O segundo eixo da investigação é a análise de sua dimensão social, ou seja, fazer aparecer as relações subjetivas e identitárias que reúnem as pessoas em rede e formam um outro Nós coletivo. Seu objetivo é revelar as dimensões: sociais, subjetivas, imateriais e intangíveis e para a constru- 
ção de um espaço de ação coletiva e compartilhada. Refere-se, também, à produção de um objeto abstrato, às relações sociais e subjetivas da ação dos atores do mundo associativo em rede telemática. Trata-se de compreender as relações de associativismo estabelecidas, para identificar as relações subjetivas de confiança, de interação, formas de divisão do poder e de compartilhamento da ação.

\section{O método de investigação}

Essa é a problemática que nos deu os caminhos para o desenvolvimento do método de investigação. O dilema das ciências sociais está sempre posicionado em torno da adoção de métodos mais quantitativos ou qualitativos (KAUCHAKJE, 2006). A diversidade na escolha de teorias e procedimentos foi o ponto de partida que permitiu a formulação do método aqui proposto. Nesse sentido, foram reconhecidas a teoria da SNA e a teoria da ação social como passíveis de combinação e de se constituírem indicadores para ampliar as possibilidades de acerto na investigação proposta.

O debate nas ciências sociais sobre o uso de métodos quantitativos e qualitativos é bem conhecido; ele está inscrito nos limites das categorias analíticas de estrutura e de processo. Como bem observa Ribeiro (1991), os cientistas sociais que defendem a adoção da ação social reconhecem que as estruturas se constituem em totalidades vazias, sem sujeitos sociais com consciência dos seus atos, sendo necessária a compreensão dos valores sociais e culturais como elementos que constituem a ação social. Isso significa valorizar a ação social por meio da subjetividade, compreendida como parte constitutiva da relação social. Importa compreender, como alerta a autora, o processo de como uma ação possível está inserida na pluralidade de vida que dá lugar à análise das práticas sociais.

A abordagem estruturalista considera que a estrutura determina as práticas sociais, ou seja, a sociedade é lida a partir de interpretações que valorizam as relações estruturais como determinantes das práticas políti- 
cas dos atores. Quando as relações sociais são entendidas como derivadas de relações estruturais, a totalidade estrutural é capaz de definir os processos relacionais entre os atores dessa totalidade.

Esse é o debate das ciências sociais, que opõem a abordagem estruturalista à abordagem da ação social. A estruturalista se propõe a interpretar a dimensão estrutural dos processos sociais; e a social revela a dimensão cotidiana, focada na análise das práticas cotidianas no mundo da vida e resultante de uma análise qualitativa e não apenas quantitativa. Não é nosso objetivo fazer um tratado sobre as duas abordagens, mas somente contribuir para a análise das redes tecnossociais a partir de um posicionamento analítico resultante de uma compreensão de que ambas nos ajudam a decompor o objeto do conhecimento e se aplicam à interpretação de sua dimensão objetiva e técnica, e de sua dimensão subjetiva e social.

Para analisar a arquitetura constituída pelas interações entre os atores, foi aplicada a teoria estruturalista. Essa metodologia evidencia os processos que possibilitam as conexões entre os atores participantes da rede, em estruturas mais flexíveis e autônomas, e permite que se visualize a estrutura das conexões entre os atores e que definem a estrutura das redes. Nessa abordagem, a estrutura define a relação social. Esse posicionamento analítico forma uma escola do pensamento denominada Social Network Analyse - SNA, cujo princípio é a matemática formal e estatística. A utilização dessa teoria revela os princípios de aplicação da análise estruturalista aos processos de constituição do social (PENNA; FREY, 2006)².

2 Essa teoria tem por objetivo decompor e recompor o objeto do conhecimento no sentido de aplicar regras e buscar as leis que determinam o funcionamento do conjunto da sua totalidade. Trata-se de encontrar elementos analíticos que nos explicitem as suas formas e que possibilitem a compreensão da lógica de sua ordem. É preciso estar atento para não confundir a teoria estruturalista aqui usada com a teoria do estruturalismo da escola francesa do capitalismo. $\mathrm{O}$ estruturalismo que tem em Althusser, a sua representação primeira, tem por objetivo fazer a analise da formação social lida a partir de processos objetivos que prescindem da ação dos sujeitos, sendo que nessa formulação da estrutura social não existe sujeito criativo. Quando o fundamental da analise reconhece que o conceito de modo de produção de Marx envolve três estruturas ou níveis : econômico, político e ideológico intima e internamente combinados que formam a estrutura do modo de produção capitalista. 
A aplicação da SNA permite mapear a arquitetura das redes tecnossociais pelas conexões realizadas pela quantidade de nós, pela institucionalidade dos atores e pelos fluxos de comunicação. Eles representam os laços que constituem as relações entre os atores e podem ser indicativos dos vínculos que se estabelecem entre os mesmos. Ela também revela a localização nos atores na hierarquia das redes e representa a centralidade que expressa a importância dos atores. Além da localização física, é possível reconhecer a localização simbólica por uma leitura do capital econômico, social e político acumulado pelos atores. As redes são desenhadas pela integração de subgrupos formadores das redes tecnossociais. É possível perceber uma arquitetura de relações entre os diferentes quando formam as redes. Cada um se organiza através de um leque de articulações - uma articulação entre os diferentes grupos que conformam a totalidade das redes. São estruturas mais simples que formam uma estrutura complexa; atores que se posicionam de modo semelhante na rede formam um bloco e definem as posições dos atores e as relações entre os indivíduos que participam das redes (PENNA; FREY, 2006).

A aplicação da teoria do SNA permitiu então encontrar um método de trabalho para desenhar os nós que formam as conexões entre as redes, bem como desenhar os contornos de sua ação em torno de organizações e de políticas públicas. Isso quer dizer que ele indica como um ator se conecta ao outro, através da leitura dos links que estão disponíveis em sua página na Internet (PENNA; FREY, 2006).

Para analisar a dimensão social dos atores, a pesquisa se desenvolveu de forma a utilizar a abordagem da teoria da ação social, que compreende os princípios do funcionamento do tecido social como derivados da ação prática dos atores dos grupos sociais. Essa abordagem marca os princípios de compreensão do processo social lido nas práticas cotidianas dos atores participantes dos grupos em objeto de investigação (EGLER, 2006a). 
Essa abordagem nos permitiu desenhar a complexidade das relações estabelecidas no mundo associativo das redes telemáticas, que conformam a complicada arquitetura da organização de redes tecnossociais, e do papel das redes de instituições governamentais e do mundo associativo voltado para a formulação e a realização de políticas públicas para a gestão urbana.

A diversidade metodológica permite uma abrangência sobre o objeto de conhecimento e a capacidade de abordar as diferentes dimensões das redes tecnossociais e sua diversidade nos diferentes contextos examinados.

Essa decupagem do objeto do conhecimento é apenas de natureza metodológica, cujo desafio é reconstruir a sua totalidade por meio de procedimentos analíticos. Esse foi o processo que mobilizou a nossa ação analítica no desdobramento da pesquisa, quando o nosso objetivo foi trabalhar para compreender as múltiplas determinações técnicas e sociais e suas inter-relações que definem as formas de constituição das redes tecnossociais.

\section{As redes tecnossociais nas cidades de São Paulo e Rio de Janeiro ${ }^{3}$}

Os resultados da pesquisa realizada no Rio de Janeiro e em São Paulo $^{4}$ estão apresentados no corpo desse trabalho, quando foi possível avançar em direção a uma análise cujo objetivo fosse recompor essa totalidade e apresentar as suas implicações políticas.

A literatura sobre redes sociais compreende que as redes foram criadas para mobilizar e desenvolver ações conjuntas, com o objetivo de promover mudanças na sociedade. Elas se mobilizam a partir da percepção socialmente compartilhada de que existem situações que colocam em

3 Participaram da realização da pesquisa nas cidades do Rio de Janeiro e São Paulo os estudantes Paula Sobrino, Thiago Mattioli e Carlos Eduardo Pinho, sob nossa coordenação.

4 Essa pesquisa foi desenvolvida em sete cidades além do Rio de Janeiro e de São Paulo ela foi realizada em Curitiba e Porto Alegre, sob coordenação de Klaus Frey, Cuauhtémoc e Toluca no México, sob coordenação de Sergio Gonzáles e Bogotá na Colômbia, sob coordenação de Alexandra Gallego Rodrigues.Sendo a coordenação geral da pesquisa realizada sob nossa responsabilidade. 
risco a sociedade e exigem a sua participação social, para além da intervenção do Estado, seja pela defesa do meio ambiente, dos direitos humanos ou da inclusão digital. O foco da nossa análise é compreender como a invenção de tecnologias transforma a capacidade de conectividade e articulação das redes sociais pré-existentes. O levantamento realizado na Internet deixa claro que estamos diante de um espaço complexo, organizado pela articulação de organizações de estado, de instituições do conhecimento, de entidades sociais, de capital privado e de pessoas.

A leitura de Habermas (1996) orienta a nossa análise para compreender como o Estado é uma forma de organização do poder na sociedade, sendo historicamente determinada. Essa compreensão é importante porque separa o conceito de Estado do conceito de poder. Habermas examina como existe um esgotamento das formas de organização do Estado - isto está acontecendo em diferentes países da sociedade ocidental, desenvolvidos ou não. É preciso reinventar as formas de organização do poder de modo a se constituírem comunidades autônomas que se comunicam entre si. Essa é a razão que nos entusiasma, pois a pesquisa realizada revela formas alternativas de organização do poder constituídas a partir da ação social.

A pesquisa produziu três grandes conjuntos de informações: um primeiro, quantitativo, resultado do levantamento e da sistematização por banco de dados disponível em plataforma na Internet. O segundo é o conjunto de gráficos, que foram produzidos; e o terceiro resultou do levantamento das práticas políticas dos membros do mundo associativo virtual. A leitura dessa empiria nos permite realizar a análise apresentada a seguir, sobre as conexões que definem a estrutura da arquitetura das redes, as relações entre a tecnologia e as práticas sociais, a origem dos seus atores, as formas de organização em políticas públicas setorialmente definidas, e os agentes de seu financiamento. 
O gráfico a seguir, produzido pela utilização do programa UCINET, e NetDraw, revela a estrutura da arquitetura das redes tecnossociais para a produção de políticas públicas. Ele deve ser interpretado nas relações de comunicação que conectam os diferentes membros e que formam um novo ser coletivo articulado, tendo por objetivo a produção de políticas públicas para o desenvolvimento social. São os atos de comunicação que formam e conformam o tecido social virtual e que conecta os seus membros, formando uma nova totalidade que se move em direção a um objetivo comum de ação.

Estrutura das redes tecnossociais:

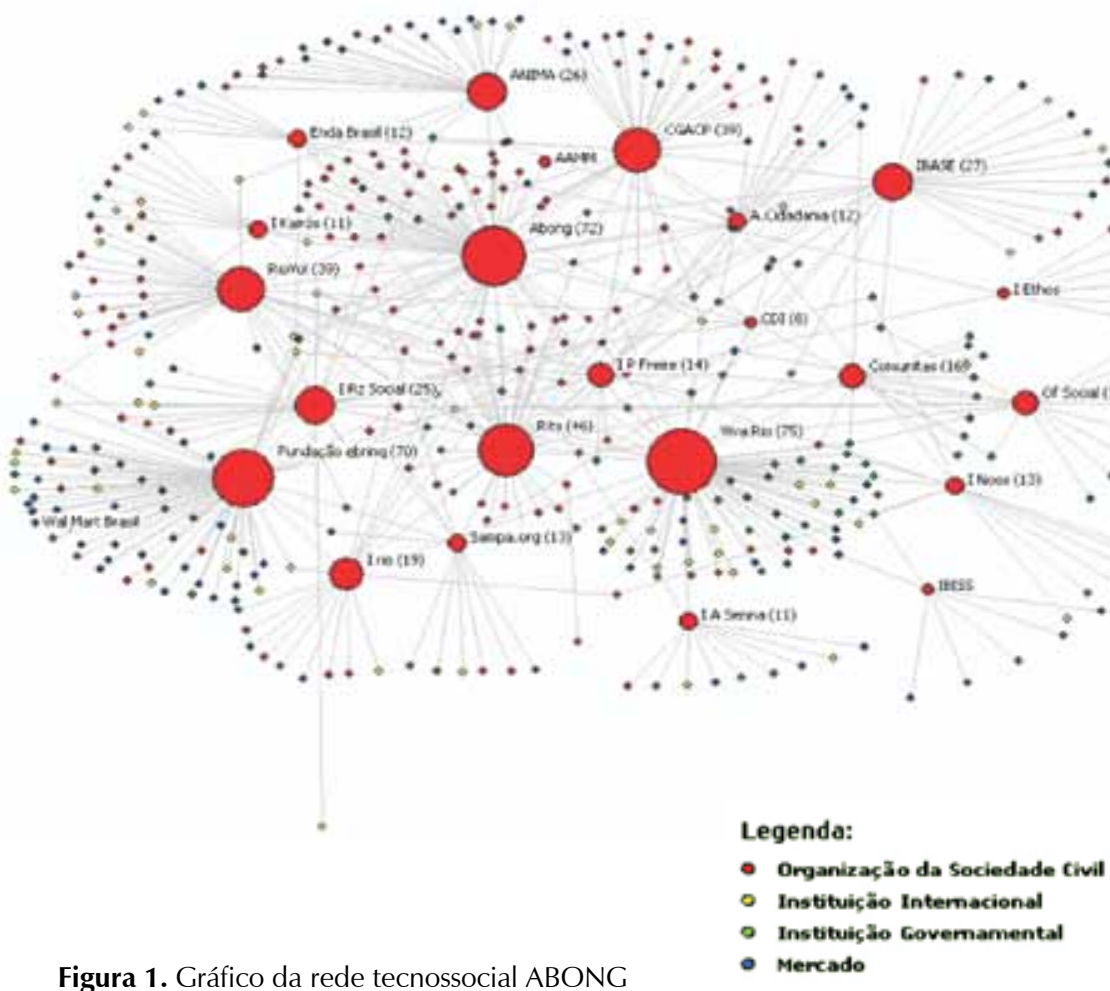


Foi possível cadastrar um total de 153 instituições, sendo que 92 atuavam na cidade do Rio de Janeiro e 61, em São Paulo. Foi relacionado um total de 1.863 parceiros das instituições que atuavam no Rio de Janeiro e 1.244, em São Paulo. Dentre esses parceiros, encontram-se organizações internacionais, governamentais, empresas públicas e privadas, assim como organizações da sociedade civil e pessoas (ASSUMPÇÃO, 2006). Isso significa dizer que a estrutura da arquitetura das redes tecnossociais é formada por redes sociais que pré-existem, e que se conectam entre si.

É preciso considerar na análise que estamos diante de relações que se estabelecem entre o vital e o virtual. O que se quer dizer é que as redes sociais que pré-existem, se conectam através do uso de tecnologias e formam as redes tecnossociais. É uma rede que se forma pela conexão entre vitalidade e virtualidade e produz uma espacialidade que desenha um espaço público formado por objetos, fluxos e ações comunicativas. Ele conecta as redes sociais pré-existentes através de fluxos comunicacionais, expande o espaço vital que se conecta ao espaço virtual, formado um espaço de alta complexidade.

A primeira coisa a destacar na pesquisa realizada é a nossa surpresa diante do grande número de organizações, entidades e pessoas que, associadas em rede, atuando no mundo associativo virtual - está muito além do que imaginávamos, quando realizamos a proposta de desenvolver a pesquisa. Com certeza, o advento de novas tecnologias redefine as possibilidades de participação, quando amplia as possibilidades de comunicação e de formação de uma esfera pública virtual, para a ação coletiva. A pesquisa realizada reitera essa possibilidade, quando apresenta evidências de novas formas de criação de espaços públicos, criados pela interação entre atores, formando redes e organizando-se em torno de políticas públicas setoriais. 
A imagem desse gráfico revela a configuração da rede tecnossocial; as retas representam os atos de comunicação criados entre os atores do mundo associativo virtual. Elas são desenhadas pelas conexões que podemos ler entre os atores, onde as conexões representam os nós das redes e são interpretadas por diferentes organizações públicas e privadas, locais e globais. A distinção dos atores é representada pelas cores (organizações da sociedade civil, governamentais e internacionais), enquanto a importância do articulador, na rede, pode ser lida pela densidade das conexões representadas pelo diâmetro da circunferência. A medida do diâmetro define a importância da articulação na rede. Como podemos observar, o posicionamento dos atores na rede pode ser hierarquizado pelo número de conexões. A leitura do gráfico revela que ocupam um lugar mais significativo nas redes sociotécnicas as seguintes instituições: Viva Rio, com 75; ABONG, com 72; e Fundação Ebing, com 70 conexões, sendo que as outras são menos conectadas.

O gráfico é uma representação importante, porque define como essa arquitetura representa a multiplicidade de atores que participam da formação desse espaço público virtual, sendo sua arquitetura fluída, móvel, líquida, flexível, que revela as relações estabelecidas nas redes tecnossociais.

Esse gráfico representa as políticas sociais, lidas na porta de entrada da $A B O N G$, e expressa a multiplicidade de atores que atuam no universo pesquisado, revelando a importância das relações de comunicação que conformam as redes tecnossociais de gestão democrática da cidade. Ele representa a multiplicidade de poderes articulados em múltiplas direções - representa a metáfora de uma rede sináptica de capilaridades onde há independência e autonomia entre as partes (FOUCAULT, 1999). Nele, as partes podem ser entendidas como comunidades auto-organizadas COmunicativamente, propostas por HABERMAS $(1987,1997)$. 
A pesquisa realizada nos fornece duas fontes primárias para a análise: o levantamento e a sua sistematização em indicadores e gráficos gerados e as entrevistas realizadas. A pesquisa produziu indicadores importantes sobre a participação dos diferentes setores; 93\% se constituem em organizações da sociedade civil, sendo que o Estado e as empresas privadas têm uma participação pouco expressiva nesse contexto.

Ali onde acontecem as práticas sociais, os atores percebem a importância das tecnologias para a formação desse espaço público virtual. Orlando Júnior é claro: "as novas tecnologias possibilitam maior densidade e operacionalidade à ideia de rede. As redes existiam, mas não tinham como se articular... Todas as decisões são tomadas por todos" ${ }^{\prime \prime}$. A nossa tendência é acreditar que as novas tecnologias potencializaram as possibilidades de aglutinar pessoas e instituições em torno de políticas públicas setoriais de ação e redefinem as formas de organização das redes sociais, ampliando sua capacidade de interação. Elas se constituem em instrumento de democratização dos processos de decisão, porque permitem a comunicação de todos a todos e a tomada de decisão coletiva.

As escalas de atuação nos fazem perceber que a maioria (52\%) tem uma ação constituída nacionalmente e 35\%, localmente, sendo que é bastante expressiva a participação de organizações internacionais - em torno de $15 \%$, na concepção, implementação e financiamento de políticas de desenvolvimento social. Essas articulações que nos propomos a examinar revelam a complexidade das articulações que observamos entre o local e o global. Trata-se de um dado que reitera a nossa percepção de que a invenção de tecnologias de comunicação e informação ampliam a capacidade de organização social no lugar; constituem novo processo que articula o local com o global; e resultam na compreensão de um novo fenômeno que denominamos de glocalização (DUARTE, 2006). A

5 Entrevista realizada com Orlando Junior, membro do Conselho Diretor do Fórum da Reforma Urbana, em 23/03/2006. 
categoria glocalização está referida às relações que se estabelecem entre o local e o global, constituindo um processo que une a globalização com a localização, formando nova totalidade composta por objetos e atores que se conectam por fluxos de comunicação e que formam nova totalidade complexa que une processos globais e locais.

\section{Tecnologia e práticas sociopolíticas dos atores}

Um dos pontos mais importantes da pesquisa era saber a forma de utilização de tecnologias de informação e comunicação dos atores e seus afeitos sobre as práticas sociais. Os indicadores da pesquisa revelam que a maioria - mais de 90\% - dos atores utilizam e-mail e sítios na Internet. Os sítios são principalmente utilizados para difundir junto à sociedade os resultados alcançados pelas organizações. Isso significa que os atos de comunicação interativa resultam do uso de programas de correio eletrônico, que permite, de fato, o maior grau de conectividade e interação das redes.

São as diferentes possibilidades dadas pelo uso da Internet, de tecnologias de voz e de imagem, que irão transformar, de forma mais decisiva, as possibilidades de fazer as conexões entre os membros das redes sociais. Dessa forma, podemos perceber que são as diferentes formas de estabelecer as conexões entre os membros, realizadas por meio do correio eletrônico, dos sítios e, mais recentemente da tecnologia de voz, que certamente irão revolucionar as formas de comunicação e possibilidades de conexão em rede. Hoje, a possibilidade de comunicar é ampliada, sendo que cada organização pode, a partir de sua própria estrutura, estabelecer canais de comunicação para "dentro" e para "fora". 


\section{A lógica setorial das redes tecnossociais}

Em torno de quais objetos de ação se organizam as redes tecnossociais de gestão democrática da cidade?

Para avançar na análise das redes tecnossociais, era importante definir os seus objetos comuns de ação. Por essa razão, a complexidade de objetos de ação encontradas no ciberespaço e na pesquisa exigiu que definíssemos essas categorias de análise. Para tanto, foi estabelecido que o desenvolvimento urbano deveria ser apreendido em sua complexidade. E ainda, que deveriam ser consideradas as organizações sociais que atuam na formulação e execução de políticas públicas, considerando-se as ações dos atores em benefício do desenvolvimento social, da criação de empregos, da defesa de minorias, da produção cultural, da preservação ambiental e do desenvolvimento da infraestrutura urbana e habitacional (PENNA; FREY, 2006).

Se analisarmos as redes voltadas para as políticas públicas, podemos perceber como elas se organizam em torno de objetos compartilhados de ação, lidos em políticas publicas setoriais. Para investigar os projetos formulados de forma objetiva, a pesquisa realizada investigou as diferentes políticas públicas setoriais. As redes resultam de uma ação que constitui uma rede tecnossocial para a produção de políticas públicas setoriais de um conjunto de organizações: em torno de $82 \%$ para o desenvolvimento social; de $50 \%$ para a defesa dos direitos humanos; e quase 30\% para a defesa do meio ambiente - as outras categorias têm menor importância de ação.

Essa divisão temática conduz a nossa análise à compreensão de que estamos diante de novas formas de organização da produção de políticas públicas, que nos permitem observar formas mais flexíveis do que as grandes estruturas burocráticas das organizações governamentais. Nelas, vamos encontrar um número menor de pessoas associadas em redes e atuando em projetos. As pessoas e as instituições se reúnem por conta de um objeto de ação em comum, cujo resultado são novas possibilida- 
des de organização social, mais flexíveis, de temporalidade definida e de coesão social, produzidas por interesses construídos a partir de uma identidade compartilhada.

O desvendamento dessa ordem, na organização das redes tecnossociais, é uma das importantes descobertas na realização dessa pesquisa. Os gráficos complementam a representação dessa ação ordenada por meio de políticas públicas setoriais.

Na configuração dos gráficos, quase mapas, as formas de ordenação dos atores em torno das políticas estão expressas claramente. O gráfico da política social reúne entidades representantes de políticas de ação em praticamente todas as áreas, como educação, saúde, gênero, étnico etc. - com 429 instituições, seguido com 171 de política econômica. O gráfico da política social é o mais heterogêneo, devido à abrangência de sua definição, uma vez que nesse estão incluídas políticas de educação, saúde, combate a fome e outros. A participação dos diversos setores é bem distribuída. Diferente do gráfico da política econômica, apresentado abaixo, no qual há uma predominância mais forte do terceiro setor. Os gráficos de política social são mais densos; há mais instituições intermediárias entre as demais do que no de política econômica, abaixo apresentada. Neste, há poucas instituições intermediárias, ou seja, na ausência de determinadas instituições, as subredes, ou subestruturas, ficariam ilhadas dos demais (MATIOLLI, 2006). 
Gráfico da política econômica

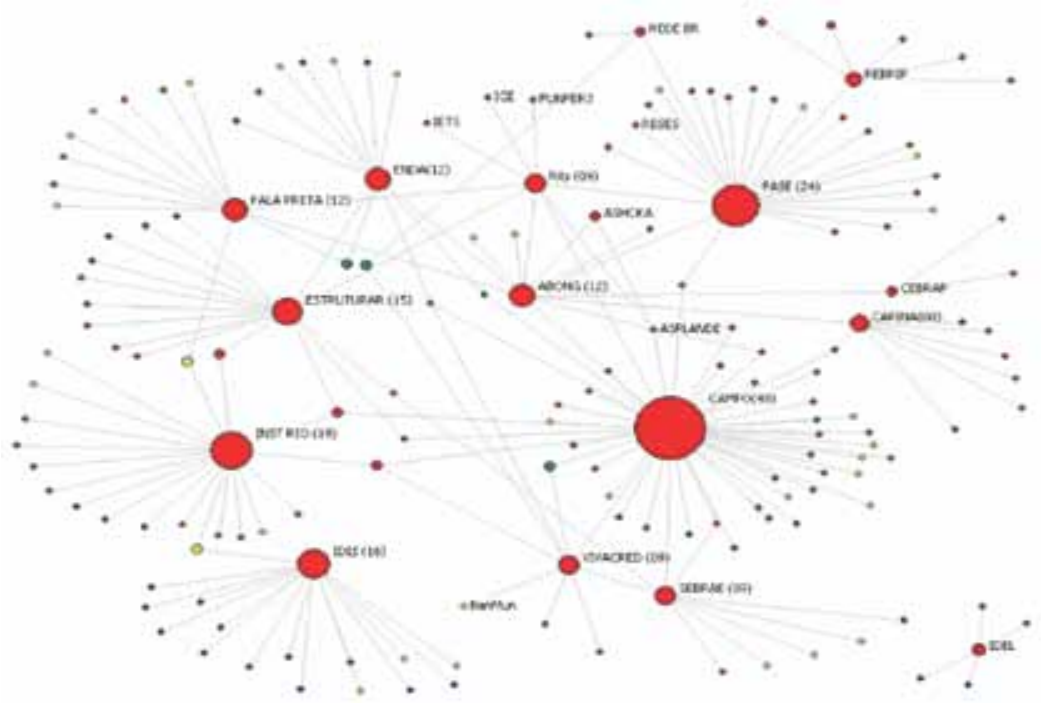

\section{Legenda:}

- Organização da Sociedade Civil

- Instituịça Intemacional

- Instituị̧ào Govemamental

- Mercado

Figura 2. Gráfico da rede tecnossocial de Política Econômica.

Parceiros, financiadores e grupos sociais beneficiados

Era necessário saber quem são os atores que participam da construção das redes. Para atingir tal objetivo, foi realizado um levantamento para definir os parceiros e patrocinadores das redes e os grupos sociais que haviam sido beneficiados pelos projetos e programas de ação. 
A redes são formadas, em sua grande maioria, por parcerias compostas por organizações que atuam de forma objetiva para produzir práticas de ação política associadas a projetos, ideologias e identidades. Isso quer dizer que os processos de associação se definem através de uma ação que tem por objetivo produzir transformações sociais, através de projetos de intervenção claramente enunciados em torno de políticas setoriais. Ou ainda, as redes que se conectam por uma ideologia compartilhada, como é o caso das organizações que lutam pela igualdade econômica e liberdade política. Além disso, podemos ler as redes que se constituem por afinidade identitária, quando o poder de associação é dado por uma identidade compartilhada, como é o caso de redes que lutam pelos direitos das pessoas portadoras de deficiências ou ainda das minorias étnicas.

Fazem parte dessas parcerias, também, outros tipos de associação, cujo objetivo é produzir a mobilização para a criação de um sentido comum no processo de transformação social. As redes resultam de uma forma de organização com o objetivo de realizar programas e de, também, construir uma identidade coletiva em torno de projetos compartilhados de ação.

A investigação realizada identificou dois grandes subgrupos de ação. As redes tecnossociais observadas tinham, na maioria das vezes, objetos abstratos de ação em comum - a busca da transformação social, a criação de igualdades, a luta pelos direitos humanos, a busca de melhorias nas condições de vida; e outros projetos, como políticas de desenvolvimento social, defesa dos direitos humanos, proposição de políticas culturais, implantação de infraestrutura urbana para saneamento, programas de sustentabilidade para o meio ambiente - ou seja, ações e projetos de associações ideológicas. Por essa razão, essa distinção nos ajuda a perceber que podemos ter diferentes formas de associação em rede, a partir de projetos concretos e a partir de associações com um objeto comum de ação abstrato. Trata-se de ver que existem dois tipos de redes: uma primeira para alcançar projetos 
claramente objetivados; e uma segunda, cujo objeto de ação é a criação de uma identidade coletiva, de natureza subjetiva.

Foi possível, ainda, identificar que, em $68 \%$ dos casos, as instituições se organizam por projetos de ação; e os outros $22 \%$ por cento, pela formação de uma identidade coletiva, na construção de um processo de transformação social. Esse dado é importante porque fala do objeto que determina um espaço comum de compartilhamento, quando as redes se organizam para uma ação concreta, como, por exemplo, cuidar de menores abandonados, alfabetizar pessoas, instalar processos de desenvolvimento econômi$\mathrm{CO}$, difundir programas culturais, constituir formas de defesa contra a violência. São inúmeros programas e projetos que se constituem em objetos de ação das redes que fazem parte do mundo associativo virtual.

As redes se estruturam por meio das articulações estabelecidas pela transversalidade dos campos e com o apoio financeiro de diferentes atores: instituições internacionais (20\%); organizações governamentais (20\%); empresas públicas (2\%); privadas (13\%); sociedade civil (50\%); e por pessoas (1\%). Compreende-se a transversalidade dos campos como a única capaz de permitir a participação de uma multiplicidade de atores e de sua diversidade na construção de novas totalidades dos sujeitos históricos. Trata-se de reunir num mesmo espaço atores originários de diversas esferas, para formar um novo espaço público para a ação compartilhada. As redes temáticas colocam em relação sujeitos, instituições, empresas e redefine a sua ação permitindo novas parcerias em torno de objetos compartilhados de ação. Por isso a tecnologia permite redefinição de totalidades sociais mais flexíveis e interativas. O progresso da tecnologia possibilita essa multiplicidade de interações e transforma as possibilidades de ação social para além das relações espaço-temporais da modernidade industrial.

Dessa forma, é constituído o tecido que forma as redes tecnossociais. Forma-se um espaço de interação entre o mundo da vida e o mundo do sistema, possibilitando novas formas de articulação entre os dife- 
rentes atores que participam dos diferentes campos (HABERMAS, 1996). As fronteiras tradicionais rompem-se, produzindo novas parcerias, na medida em que a esfera pública reúne-se com a privada e potencializa a capacidade de ação social (SANTOS, 2003).

Finalmente, a pesquisa teve por objetivo identificar os programas e projetos de ação que beneficiam os grupos sociais. Estes podem ser reconhecidos nas seguintes categorias: em torno de $47 \%$ para todos os grupos; $33 \%$ para os pobres; $21 \%$ para o gênero; em trono de $18 \%$ para crianças e jovens. As relações entre o virtual e o vital são estabelecidas, e as possibilidades de associação virtual não estão desconectadas da realidade. Ao contrário, elas criam espaços de mediação que ampliam a capacidade de articulação entre organizações governamentais, capital público e privado, redes sociais, para se constituírem numa nova esfera pública - resultado da associação realizada na transversalidade das esferas. A associação virtual possibilita novas estratégias de ação para a realização de projetos e programas para o desenvolvimento social.

A arquitetura da associação de atores sociais se constitui por redes telemáticas, lida em sua dimensão técnica e realizada através da infraestrutura, elas formam um novo meio de comunicação que constitui um público virtual. Na maioria das vezes, a nossa pesquisa indica como as redes telemáticas são utilizadas pelas organizações sociais pré-existentes. Trata-se, portanto, de investigar e analisar quais são os efeitos da rede telemática sobre a ação das redes sociais que atuam nos espaços urbanos em objeto de investigação.

\section{Concluindo}

As novas formas de associação por redes telemáticas resultam de novas identidades e promovem novos sentidos de pertencimento em sociedades mais complexas. As redes anunciam uma nova possibilidade de 
organização das nações, e as TICs se constituem em dispositivos tecnológicos que possibilitam o estabelecimento de espaços de mediação entre atores públicos e privados. A tecnologia amplia a capacidade de participação social; cria nova escala de associação articuladora das redes sociais; e possibilita novas formas de organização política e da ação coletiva, além de novas formas de interação entre Estado e redes sociais e uma forma alternativa de constituição do Nós e de sua totalidade. A tecnologia tem como pressuposto a ação coletiva e direta dos seus membros, ou seja, os atores unem-se para potencializar as suas possibilidades de ação diante dos problemas sociais que os colocam como principais protagonistas. Essa possibilidade de associação vai além das formas tradicionais de representação política; trata-se de eliminar a intermediação e possibilitar formas horizontais e diretas de ação e de transformação.

Os gráficos revelam a complexa arquitetura das organizações públicas e privadas que participam das redes tecnossociais das políticas urbanas. É nos gráficos que podemos ler como esse mosaico de organizações é constituído de uma forma tão reticular, como um espaço dinâmico e flexível se conforma, e as formas de articulação são redefinidas. Novas totalidades políticas que lutam contra a exclusão e a degradação das condições de existência nas cidades de São Paulo e Rio de Janeiro são redesenhadas.

Estamos diante de uma nova forma de constituição de comunidades autônomas que se comunicam entre si (HABERMAS, 1988) e que são capazes de realizar uma nova divisão do trabalho, associadas a formas de financiamento, ação e produção. Essas comunidades redefinem de forma profunda a ordem das formas organizacionais de Estado que as precedem. Um novo ser coletivo constitui-se através da ação colaborativa de diferentes associações para produzir um movimento positivo de ação, em busca da realização de políticas públicas de desenvolvimento social. 
Metodologicamente, nos foi possível propor processos e procedimentos com a possibilidade de visualizar e dar forma às conexões que fazem parte dessa totalidade e que conformam a delicada arquitetura das redes tecnossociais. São canais de comunicação estabelecidos entre as organizações desse mundo virtual, que permitem a formação desse novo ser coletivo identificado por atos de comunicação. Tais redes são medidas por redes telemáticas constituídas por uma estrutura valórica compartilhada.

Os gráficos parecem ser representações do universo, cujos planetas se atraem e se coesionam, pela ação de forças físicas das constelações e que permitem um movimento simultâneo dentro do nosso universo. As redes tecnossociais podem ser representadas pela metáfora de uma constelação de astros, da qual se forma uma totalidade produzida por forças de atração durante seu movimento, em uma mesma direção, em busca de condições mais dignas para a existência humana nas cidades do nosso país. As redes tecnossociais diferem fundamentalmente das formas da arquitetura de organizações que as precedem, porque elas expandem as relações espaço-temporal. Suas conexões produzem uma articulação flexível que define uma arquitetura: reticular, líquida e móvel realizada por atos de comunicação. Estes permitem a coesão entre os seus membros e produzem um sujeito coletivo, que se forma por ações compartilhadas. Em direção à definição de formas alternativas de organização política e desenvolvimento social. Essas ações podem se constituir numa esperança para redefinir as estruturas de poder que já se encontram esgotadas e que ampliam a delegação da produção do bem comum para diferentes atores sociais, para além da máquina burocrática do Estado, reconhecendo novas formas de organização em redes tecnossociais, como sujeitos da enunciação e da transformação. 


\section{The techno-social networks and the democratization of public policies}

The purpose of this study is to examine the social and governmental organizations' increasing use of information and communication technologies (ICTs) in the management of the city. The aim is to understand how the ICTs can be used as an alternative way to redefine the relationship between state and society, replacing traditional urban policies for collaborative forms of interaction between social agents. Among the results achieved by the research, it is possible to point out the development of a methodology capable of identifying the principles of organization, coordination, connection and interaction that constitute the existence of techno-social networks. The application of the methodology in the cities of Rio de Janeiro and São Paulo presented indicators, graphs and political practices. The analysis of these data shows that the networks are constituted by a mobile, fluid and flexible architecture; and that they are organized around common political actions and formed by a collective identity that approximates the agents and the techno-social networks. The principles that mediate this cohesion are sharing, trust and solidarity, which redefine the forms of power organization toward alternatives of political organization and social development.

Keywords: Techno-social networks. Public policies. Democracy. Information and communication technologies. Social innovation.

\section{Referências}

ASSUMPÇÃO, Paula. Identificação e Mapeamento de redes tecnossociais: Rio de Janeiro e São Paulo, Relatório para a pesquisa Redes tecnossociais e gestão democrática da cidade, IPPUR/LACNIC. Rio de Janeiro, 2006.

BARTHOLO, Roberto. Você e Eu: Martin Bubber, presença e palavra. Rio de Janeiro: Garamond, 2001.

CASTELLS, Manuel. A sociedade em rede. São Paulo: Paz e Terra, 1999a.

. O poder da identidade. São Paulo: Paz e Terra, 1999b.

DUARTE, Fabio. Conectividade, acessibilidade, comunicabilidade - parâmetros conceituais para se pensar a inclusão digital. Apresentado ao Seminário Redes tecnossociais e gestão democrática da cidade, IPPUR/LACNIC, Rio de Janeiro, 2006 
EGLER, Tamara Tania Cohen. A imagem do espaço numérico. Cadernos IPPUR/ UFRJ, 2002, v. XVII , n.2, ago./dez. 2003.

. Democracia virtual na governança urbana. In: XII Congresso Brasileiro de Sociologia, 2005, Belo Horizonte. Sociologia e Realidade - Pesquisa social no século XXI, 2005.

EGLER, Tamara Tania Cohen et al. Contribuição metodológica para a pesquisa de redes técno-sociais, Bogotá, PRe-til, Investigar para fazer cidades, Bogotá, Universidade da Cidade, ano IV, no 12, jul.-nov. de 2006 a.

. O mapa das redes tecnossociais: uma experiência metodológica, Seminário "Redes tecnossociais e gestão democrática da cidade, Rio de Janeiro: IPPUR/UFRJ, maio 2006b.

EGLER, Tamara Tania Cohen; FREY, Klaus. Sociotechnical networks in urban planning and governance, World Planning Schools Congress Diversity and Multiplicity: a new agenda for the world planning community, Mexico, 2006c.

FOUCAULT, Michel. Microfísica do poder. Rio de Janeiro: Graal, 1999.

GERSTLE, Jacques. Réseaux de comunications, réseaux sociaux et réseau polítiques. In: MUSSO, Pierre. Réseaux et société. Paris: Presses Universitaires de France, 2003.

HABERMAS, Jurgen. A nova intransparência. Do esgotamento das energias utópicas. Novos Estudos CEBRAP, no. 18, 1987.

. Direito e democracia. Entre facticidade e validade. Tomo I e II. Rio de Janeiro: Tempo Brasileiro, 1997.

HARDT, M.; NEGRI, A. Império. Rio de Janeiro: Record, 2001.

KAUCHAKJE, Samira et al. Redes socio-técnicas: conceptos y análisis. Pre-til, n. 12, Bogotá, julho/novembro, 2006.

LEVY, Pierre. As tecnologias da inteligência. Rio de Janeiro: Editora 34, 1993.

. Cibercultura. São Paulo: ED 34, 1999ạ.

. A inteligência coletiva. São Paulo: Edições Loyola; ED 34, 1999 b.

MAIA, Rousiley C. M. Redes cívicas e Internet. In: EISENBERG, José; CEPIK, MarCo. Internet e política. Belo Horizonte: Editora UFMG, 2002.

MATIOLLI, Thiago. Considerações sobre os gráficos das redes tecnossociais nas cidades de São Paulo e Rio de Janeiro, Relatório para a pesquisa Redes tecnossociais e gestão democrática da cidade, Rio de Janeiro, 2006. 
OLIVEIRA, L. A. Valores deslizantes: esboço de um ensaio sobre técnica e poder. In: NOVAES, Adauto. O avesso da liberdade. São Paulo: Companhia das letras, 2002.

PENNA, Manoel Camilo; FREY, Klaus. Avaliação Estrutural de Redes Sócio-Técnicas, texto apresentado ao seminário: Redes tecnossociais e gestão democrática da cidade, IPPUR/LACNIC, Rio de Janeiro, 2006.

RIBEIRO, Ana Clara Torres. Movimentos Sociais: caminhos para defesa de uma temática ou os desafios dos anos 90. Ciências Sociais Hoje, 1991, São Paulo, ANPOCS/ Ed. Vértice, 1991.

SANTOS, Boaventura Souza. Democratizar a democracia, os caminhos da democracia participativa. Rio de Janeiro, 2003.

SANTOS, Milton. A natureza do espaço: técnica e tempo, razão e emoção. São Paulo: Hucitec, 1996.

. Técnica, espaço e tempo. Globalização e meio técnico científico. São Paulo: Editora Afilhada, 1994.

SCHERER, Warren Ilse. Redes sociais: trajetórias e fronteiras. In: DIAS, Leila; SILVEIRA, Rogério. Redes, sociedades e territórios. Santa Cruz do Sul: EDUNIC, 2005.

Recebido: $14 / 08 / 2007$

Aceite final: 04/09/2007 